\title{
A DECISÃO DA CORTE INTERAMERICANA DE DIREITOS HuMANOS NO CASO GOMES LUND E OUTROS - GUERRILHA do Araguaia
}

\author{
The decision of the Inter-American Court of Human Rights \\ in case Gomes Lund and others - The guerrilla Araguaia
}

\section{Adriana Silva Maillart}

Doutora e Mestre em Direito pela UFSC. Coordenadora do Curso de Direito, professora e pesquisadora do Programa de Mestrado em Direito da Universidade Nove de Julho (Uninove).

\section{Samyra Dal Farra Naspolini Sanches}

Doutora em Direito pela PUC-SP. Mestre em Direito pela UFSC. Pesquisadora e professora do Curso de Mestrado em Direito da Universidade Nove de Julho (Uninove). Professora colaboradora do Mestrado em Direito da Unitoledo e do Univem.

ÁreA do DIREITO: Constitucional; Internacional

Resumo: 0 presente traz o comentário sobre a decisão da Corte Interamericana de Direitos Humanos no Caso Lund e outros vs. Brasil (Guerrilha do Araguaia). Analisa a sentença da referida Corte que condenou o Estado brasileiro a implementar uma série de medidas com visto a indenizar os familiares das vitimas da Guerrilha do Araguaia e evitar que novos abusos aconteçam. A sentença, de importância histórica, perpassa por várias questões de direito internacional, tais como: competência da Corte, controle de convencionalidade, medidas protetivas e exame da anistia.

\begin{abstract}
AвSTRACT: It is a commentary of the InterAmerican Court of Human Rights decision in the Lund and others vs. Brazil Case (Araguaia Guerrilla). Analyzes the decision of that Court who condemned the Brazilian government to implement several measures to compensate the families of the victims of the Araguaia Guerrilla and prevent other abuses to happen. The historical decision goes through various international law issues, as Court's jurisdiction, control of conventionality, protective measures and amnesty.
\end{abstract}


Palavras-chave: Direitos humanos - Corte Interamericana - Anistia - Caso Araguaia - Verdade e Justiça.

SumÁrio: A) Caso - B) Comentário.
KEYwoRds: Human rights - Inter-American Court - Amnesty - Araguaia Case - Truth and Justice.

\section{A) CASO}

Corte IDH. Caso Gomes Lund e outros (Guerrilha do Araguaia) vs. Brasil. Exceções preliminares - Mérito - Reparações e custas. Sentença de 24 de novembro de 2010.

No caso Gomes Lund e outros ("Guerrilha do Araguaia"),

A Corte Interamericana de Direitos Humanos (doravante denominada "Corte Interamericana", "Corte" ou "Tribunal"), integrada pelos seguintes juízes:

- Diego García-Sayán, Presidente;

- Leonardo A. Franco, Vice-Presidente;

- Manuel E. Ventura Robles, Juiz;

- Margarette May Macaulay, Juíza;

- Rhadys Abreu Blondet, Juíza;

- Alberto Pérez Pérez, Juiz;

- Eduardo Vio Grossi, Juiz, e

- Roberto de Figueiredo Caldas, Juiz ad hoc;

Presentes, ademais,

- Pablo Saavedra Alessandri, Secretário, e

- Emilia Segares Rodríguez, Secretária Adjunta.

De acordo com os arts. 62.3 e 63.1 da Convenção Americana sobre Direitos Humanos (doravante denominada "a Convenção Americana" ou "a Convenção") e com os arts. 30, 38.6, 59 e 61 do Regulamento da Corte (doravante denominado "o Regulamento"), ${ }^{1}$ profere a seguinte sentença (a sentença é composta de 126 páginas).

1. Conforme o disposto no art. 79.1 do Regulamento da Corte, que entrou em vigor em 01.06.2010, "[o]s casos contenciosos que já houvessem sido submetidos à consideração da Corte antes de 01.01.2010 continuarão a tramitar até que neles se profira 
Começa introduzindo a causa e o objeto da controvérsia:

1. Em 26.03.2009, em conformidade com o disposto nos arts. 51 e 61 da Convenção Americana, a Comissão Interamericana de Direitos Humanos (doravante "Comissão Interamericana" ou "Comissão") submeteu à Corte uma demanda contra a República Federativa do Brasil (doravante "o Estado", "Brasil" ou "a União"), que se originou na petição apresentada, em 07.08.1995, pelo Centro pela Justiça e o Direito Internacional (Cejil) e pela Human Rights Watch/Americas, em nome de pessoas desaparecidas no contexto da Guerrilha do Araguaia (doravante também denominada "Guerrilha") e seus familiares. ${ }^{2}$ Em 06.03.2001, a Comissão expediu o Relatório de Admissibilidade 33/2001³ e, em 31.10.2008, aprovou o Relatório de Mérito 91/2008, nos termos do art. 50 da Convenção, o qual continha determinadas recomendações ao Estado. ${ }^{4}$ Esse relatório foi notificado ao Brasil em 21.11.2008, sendo-lhe concedido um prazo de dois meses para que informasse sobre as ações executadas com o propósito de implementar as recomendações da Comissão. A despeito de duas prorrogações concedidas ao Estado, os prazos para

sentença, conforme o Regulamento anterior". Desse modo, o Regulamento da Corte, mencionado na presente sentença, corresponde ao instrumento aprovado pelo Tribunal no XLIX Período Ordinário de Sessões, realizado de 16 a 25.11.2000 e reformado parcialmente no LXXXII Período Ordinário de Sessões, realizado de 19 a 31.01.2009.

2. Posteriormente, somaram-se ao caso como peticionários a Comissão de Familiares de Mortos e Desaparecidos Políticos do Instituto de Estudos da Violência do Estado, a senhora Angela Harkavy e o Grupo Tortura Nunca Mais do Rio de Janeiro.

3. No Relatório de Admissibilidade 33/2001, a Comissão declarou admissível o Caso 11.552, com relação à suposta violação dos arts. 4, 8, 12, 13 e 25, em concordância com o art. 1.1, todos da Convenção Americana, bem como dos arts. I, XXV e XXVI da Declaração Americana dos Direitos e Deveres do Homem (doravante denominada "Declaração Americana") (expediente de anexos à demanda, apêndice 3, t. III, p. 2322).

4. No Relatório de Mérito 91/2008, a Comissão concluiu que o Estado era responsável pelas violações dos direitos humanos estabelecidos nos arts. I, XXV e XXVI da Declaração Americana, bem como dos arts. 4, 5 e 7, em conexão com o art. 1.1 da Convenção Americana, em detrimento das vítimas desaparecidas; no art. XVII da Declaração Americana e art. 3, em relação com o art. 1.1 da Convenção Americana, em detrimento das vítimas desaparecidas; nos art. I da Declaração Americana e art. 5, em conexão com o art. 1.1 da Convenção Americana, em detrimento dos familiares dos desaparecidos; no art. 13, em conexão com o art. 2 da Convenção Americana, em detrimento dos familiares dos desaparecidos; no art. XVIII da Declaração Americana e arts. 8.1 e 25 da Convenção Americana, em relação com os arts. 1.1 e 2 da mesma Convenção, em detrimento das vítimas desaparecidas e de seus familiares, em virtude da aplicação da Lei de Anistia, nos arts. XVIII da Declaração Americana e arts. 8.1 e 25, em relação com o art. 1.1 da Convenção Americana, em detrimento das vítimas desaparecidas e de seus familiares, em virtude da ineficácia das ações judiciais não penais interpostas no marco do presente caso (expediente de anexos à demanda, apêndice 3, t. VII, p. 3655). 
que apresentasse informações sobre o cumprimento das recomendações transcorreram sem que a elas fosse dada uma "implementação satisfatória". Diante disso, a Comissão decidiu submeter o caso à jurisdição da Corte, considerando que representava "uma oportunidade importante para consolidar a jurisprudência interamericana sobre as leis de anistia com relação aos desaparecimentos forçados e à execução extrajudicial e a consequente obrigação dos Estados de dar a conhecer a verdade à sociedade e investigar, processar e punir graves violações de direitos humanos". A Comissão também enfatizou o valor histórico do caso e a possibilidade de o Tribunal afirmar a incompatibilidade da Lei de Anistia e das leis sobre sigilo de documentos com a Convenção Americana. A Comissão designou como delegados os senhores Felipe González, Comissário, e Santiago A. Canton, Secretário Executivo; como assessores jurídicos, a senhora Elizabeth Abi-Mershed, Secretária Executiva Adjunta, e os advogados Lilly Ching Soto e Mario López Garelli, especialistas da Secretaria Executiva.

2. Conforme salientou a Comissão, a demanda se refere à alegada "responsabilidade [do Estado] pela detenção arbitrária, tortura e desaparecimento forçado de 70 pessoas, entre membros do Partido Comunista do Brasil (...) e camponeses da região, (...) resultado de operações do Exército brasileiro empreendidas entre 1972 e 1975 com o objetivo de erradicar a Guerrilha do Araguaia, no contexto da ditadura militar do Brasil (1964-1985)". A Comissão também submeteu o caso à Corte porque, "em virtude da Lei 6.683/1979 (...), o Estado não realizou uma investigação penal com a finalidade de julgar e punir as pessoas responsáveis pelo desaparecimento forçado de 70 vítimas e a execução extrajudicial de Maria Lúcia Petit da Silva (...); porque os recursos judiciais de natureza civil, com vistas a obter informações sobre os fatos, não foram efetivos para assegurar aos familiares dos desaparecidos e da pessoa executada o acesso a informação sobre a Guerrilha do Araguaia; porque as medidas legislativas e administrativas adotadas pelo Estado restringiram indevidamente o direito de acesso à informação pelos familiares; e porque o desaparecimento das vítimas, a execução de Maria Lúcia Petit da Silva, a impunidade dos responsáveis e a falta de acesso à Justiça, à verdade e à informação afetaram negativamente a integridade pessoal dos familiares dos desaparecidos e da pessoa executada". A Comissão solicitou ao Tribunal que declare que o Estado é responsável pela violação dos direitos estabelecidos nos arts. 3. (direito ao reconhecimento da personalidade jurídica), 4. (direito à vida), 5. (direito à integridade pessoal), 7. (direito à liberdade pessoal), 8. (garantias judiciais), 13 (liberdade de pensamento e expressão) e 25 (proteção judicial), da Convenção Americana sobre Direitos Humanos, em conexão com as obrigações previstas nos arts. 1.1 (obrigação geral de respeito e garantia dos direitos humanos) e 2 (dever de adotar disposições de direito interno) da mesma Convenção. Finalmente, solicitou à Corte que ordene ao Estado a adoção de determinadas medidas de reparação.

3. Em 18.07.2009, o Grupo Tortura Nunca Mais do Rio de Janeiro, a Comissão de Familiares de Mortos e Desaparecidos Políticos do Instituto de Estudos da Vio- 
lência do Estado e o Centro pela Justiça e o Direito Internacional (doravante denominados "representantes") apresentaram seu escrito de solicitações, argumentos e provas (doravante denominado "escrito de solicitações e argumentos"), nos termos do art. 24 do Regulamento. Nesse escrito, solicitaram ao Tribunal que declare, "[e] $\mathrm{m}$ relação ao desaparecimento forçado das [supostas] vítimas (...) e à total impunidade referente aos fatos", a responsabilidade internacional do Estado brasileiro pela violação dos arts. 3, 4, 5, 7, 8 e 25 da Convenção, todos em conexão com os arts. 1.1 e 2 do mesmo instrumento, bem como dos arts. 1, 2, 6 e 8 da Convenção Interamericana para Prevenir e Punir a Tortura (doravante denominada "Convenção Interamericana contra a Tortura"); dos arts. 8 e 25, em conexão com os arts. 1.1 e 2 da Convenção Americana; dos arts. 1, 6 e 8 da Convenção Interamericana contra a Tortura pela falta de investigação e da devida diligência nos procedimentos de âmbito interno; dos arts. 1.1, 2, 13, 8 e 25 da Convenção pelas restrições indevidas ao direito de acesso à informação; dos arts. 1.1, 8, 13 e 25 da Convenção pela violação do direito à verdade; e do art. 5 da Convenção pela violação da integridade pessoal dos familiares das supostas vítimas desaparecidas. Solicitaram, por conseguinte, à Corte que ordene diversas medidas de reparação. Os familiares de 48 supostas vítimas, mediante poderes de representação outorgados em diversas datas, designaram como seus representantes legais as organizações já mencionadas, as quais são representadas, por sua vez, pelas senhoras Cecília Maria Bouças Coimbra, Elizabeth Silveira e Silva e Victoria Lavínia Grabois Olímpio (Grupo Tortura Nunca Mais); Criméia Alice Schmidt de Almeida (Comissão de Familiares de Mortos e Desaparecidos Políticos do Instituto de Estudos da Violência do Estado); Viviana Krsticevic, Beatriz Affonso, Helena Rocha e pelo senhor Michael Camilleri (Cejil).

4. Em 31.10.2009, o Estado apresentou um escrito no qual interpôs três exceções preliminares, contestou a demanda e formulou observações sobre o escrito de solicitações e argumentos (doravante denominado "contestação da demanda"). O Estado solicitou ao Tribunal que considere fundamentadas as exceções preliminares e, por conseguinte: (a) reconheça a incompetência ratione temporis para examinar as supostas violações ocorridas antes do reconhecimento da jurisdição contenciosa da Corte pelo Brasil; (b) declare-se incompetente, em virtude da falta de esgotamento dos recursos internos; e (c) arquive de imediato o presente caso, ante a manifesta falta de interesse processual dos representantes. Subsidiariamente, quanto ao mérito, o Brasil solicitou ao Tribunal que reconheça "todas as ações empreendidas no âmbito interno" e "julgue improcedentes os pedidos [da Comissão e dos representantes], uma vez que está sendo construída no país uma solução, compatível com suas particularidades, para a consolidação definitiva da reconciliação nacional". O Estado designou o senhor Hildebrando Tadeu Nascimento Valadares como agente e as senhoras Márcia Maria Adorno Cavalcanti Ramos, Camila Serrano Giunchetti, Cristina Timponi Cambiaghi e Bartira Meira Ramos Nagado, bem como os senhores Sérgio Ramos de Matos Brito e Bruno Correia Cardoso, como agentes assistentes. 
5. Em conformidade com o art. 38.4 do Regulamento, em 11 e 15.01.2010, a Comissão e os representantes apresentaram, respectivamente, suas alegações às exceções preliminares opostas pelo Estado.

E conclui:

30. Finalmente é prudente lembrar que a jurisprudência, o costume e a doutrina internacionais consagram que nenhuma lei ou norma de direito interno, tais como as disposições acerca da anistia, as normas de prescrição e outras excludentes de punibilidade, deve impedir que um Estado cumpra a sua obrigação inalienável de punir os crimes de lesa-humanidade, por serem eles insuperáveis nas existências de um indivíduo agredido, nas memórias dos componentes de seu círculo social e nas transmissões por gerações de toda a humanidade.

31. É preciso ultrapassar o positivismo exacerbado, pois só assim se entrará em um novo período de respeito aos direitos da pessoa, contribuindo para acabar com o círculo de impunidade no Brasil. É preciso mostrar que a Justiça age de forma igualitária na punição de quem quer que pratique graves crimes contra a humanidade, de modo que a imperatividade do Direito e da Justiça sirvam sempre para mostrar que práticas tão cruéis e desumanas jamais podem se repetir, jamais serão esquecidas e a qualquer tempo serão punidas.

\section{B) COMEnTÁRIO}

A Corte Interamericana de Direitos Humanos, em paradigmática sentença proferida em 24.11.2010, no caso Lund e outros vs. Brasil (Guerrilha do Araguaia), condenou o Estado brasileiro a implementar uma série de medidas com vistas a indenizar os familiares da vítimas dos fatos ocorridos e esclarecer e evitar que novos aconteçam.

O Caso Araguaia, foi resultado de operações do Exército brasileiro empreendidas entre 1972 e 1975 naquela região com o objetivo de erradicar a Guerrilha do Araguaia, no contexto da ditadura militar do Brasil (1964-1985). Consistiu na detenção arbitrária, tortura e desaparecimento forçado de 70 pessoas, entre membros do Partido Comunista do Brasil e camponeses da região.

Em 26.03.2009 a Comissão Interamericana de Direitos Humanos submeteu à Corte uma demanda contra o Brasil, que se iniciou pelo Centro pela Justiça e o Direito Internacional (Cejil) e pela Human Rights Watch/Americas, em nome de pessoas desaparecidas no contexto da Guerrilha do Araguaia e seus familiares. Após somaram-se ao caso a Comissão de familiares de Mortos e Desaparecidos Políticos do Instituto de Estudos da Violência do estado, a senhora Angela Harkavy e o Grupo Tortura Nunca Mais. Em 06.03.2001, a Comissão expediu o Relatório de Admissibilidade e, em 31.10.2008, aprovou o Relatório de Mérito o qual continha determinadas recomendações ao Estado. 
Após vários trâmites e prazos concedidos ao Brasil para que informasse sobre as ações executadas com o propósito de implementar as recomendações da Comissão, isso não foi feito de forma satisfatória, o que levou a Comissão a submeter o caso à jurisdição da Corte Interamericana de Direitos Humanos, enfatizando que esta seria "uma oportunidade importante para consolidar a jurisprudência interamericana sobre as leis de anistia com relação aos desaparecimentos forçados e à execução extrajudicial e a consequente obrigação dos Estados de dar a conhecer a verdade à sociedade e investigar, processar e punir graves violações de direitos humanos". 5

A Comissão solicitou ao Tribunal que declarasse que o Estado brasileiro foi responsável pela violação dos direitos estabelecidos nos arts. 3 (direito ao reconhecimento da personalidade jurídica), 4 (direito à vida), 5 (direito à integridade pessoal), 7 (direito à liberdade pessoal), 8 (garantias judiciais), 13 (liberdade de pensamento e expressão) e 25 (proteção judicial), da Convenção Americana sobre Direitos Humanos, em conexão com as obrigações previstas nos arts. 1.1 (obrigação geral de respeito e garantia dos direitos humanos) e 2 (dever de adotar disposições de direito interno) da mesma Convenção. Também solicitou à Corte que ordenasse ao Estado a adoção de determinadas medidas de reparação.

A sentença proferida pela Corte, além da importância histórica, enfrenta e resolve uma série de questões de suma importância para o Direito Internacional dos Direitos Humanos, das quais destacam-se:

A competência da Corte está prevista no art. 62.1 da Convenção Americana de Direitos Humanos, o qual reza que será levada em consideração a data de reconhecimento da competência por parte do Estado, os termos em que se deu esse reconhecimento e o princípio de irretroatividade, disposto no art. 28 da Convenção de Viena sobre o Direito dos Tratados de 1969.

$\mathrm{Na}$ sua contestação, o Brasil preliminarmente alegou a incompetência da Corte para julgar o caso, uma vez que o reconhecimento da competência da Corte só se deu em 10.12.1998 e, em sua declaração, indicou que o Tribunal só teria competência para os "fatos posteriores" a esse reconhecimento. A Corte entendeu que realmente não poderia exercer sua competência quando os fatos alegados ou a conduta do Estado, sejam anteriores a esse reconhecimento da competência. Por esta razão, ficou excluída a competência da Corte para julgar a execução extrajudicial da senhora Maria Lúcia Petit da Silva, cujos restos mortais foram identificados em 1996, bem como qualquer outro fato anterior a esse reconhecimento.

5. Sentença disponível em: [www.corteidh.or.cr]. 
Porém, a Corte se julgou competente para analisar os desaparecimentos forçados, uma vez que em sua jurisprudência já estabeleceu que os atos de caráter contínuo ou permanente perduram durante todo o tempo em que o fato continua, ou seja, o ato de desaparecimento se inicia com a privação da liberdade da pessoa e a falta de informação sobre seu destino, e permanecem até quando não se conheça o paradeiro da pessoa desaparecida e os fatos que não tenham sido esclarecidos.

A Corte também entendeu que tem competência para analisar os supostos fatos e omissões do Estado, no que diz respeito à falta de investigação, julgamento e sanção das pessoas responsáveis pelos desaparecimentos forçados e execução extrajudicial; bem como pelas restrições ao direito de acesso à informação, e o sofrimento dos familiares.

Assim, julgou o Estado responsável pelo desaparecimento forçado e, consequentemente pela violação dos direitos ao reconhecimento da personalidade jurídica, à vida, à integridade pessoal e à liberdade pessoal, previstos nos arts. 3, 4, 5 e 7 da Convenção Americana sobre Direitos Humanos.

Também considerou o Estado responsável pela violação dos direitos às garantias judiciais e à proteção judicial previstos nos arts. 8.1 e 25.1 da Convenção Americana sobre Direitos Humanos, devido à falta de investigação dos fatos e pela falta de julgamento e sanção dos responsáveis.

Considerou ainda, o Estado responsável pela violação do direito à liberdade de pensamento e de expressão previsto no art. 13 da Convenção Americana sobre Direitos Humanos, pela violação do direito a buscar e a receber informação, bem como do direito de conhecer a verdade sobre os fatos ocorridos. Também considerou o Estado responsável pela violação dos direitos às garantias judiciais estabelecidos no art. 8.1 da Convenção Americana, por exceder o prazo razoável para a apuração dos fatos.

Na sua contestação, o Brasil, sustentando a falta de esgotamento dos recursos internos, alegou que seria preciso dar tempo para que o STF se pronunciasse na ação de arguição de descumprimento de preceito fundamental interposta pela Ordem dos Advogados do Brasil em outubro de 2008.

$\mathrm{Na}$ ação, a OAB solicitou que o STF conferisse à Lei de Anistia uma interpretação conforme com a Constituição Federal de 1988, com o objetivo de declarar que a anistia concedida por essa lei aos crimes políticos ou conexos não se estenderia aos crimes comuns praticados pelos agentes de repressão contra opositores políticos, durante o regime militar.

Mais tarde, o Brasil comunicou que, em 29.04.2010, o STF considerou improcedente a ADPF 153/DF, declarando que "a Lei de Anistia representou, em 
seu momento, uma etapa necessária no processo de reconciliação e redemocratização do país" e que "não se tratou de uma autoanistia".

Baseado neste fato novo, o Brasil questionou a competência da Corte Interamericana para revisar decisões adotadas pelas mais altas cortes de um Estado. Alegou que com a decisão da ADPF 153/DF, ocorreu o esgotamento dos recursos internos, porém devido o caráter subsidiário da atuação dos sistemas regionais de proteção aos direitos humanos, estes não podem atuar como tribunais de alçada e julgar alegados erros, de fato ou de direito, cometidos por tribunais domésticos que tenham atuado dentro de suas competências.

Acertadamente a Corte Interamericana afirmou que o julgamento quanto à violação ou não, pelo Estado, de suas obrigações internacionais, é sim de sua competência, podendo revisar, inclusive, as decisões de tribunais superiores, para estabelecer sua compatibilidade com a Convenção Americana.

Essa decisão da Corte consagra o processo de universalização dos direitos humanos iniciado após a Segunda Guerra mundial, quando os direitos humanos tornam-se uma legítima preocupação internacional, encerrando-se a concepção de que a forma como o Estado tratava seu povo era concebida como um problema de jurisdição doméstica devido à soberania.

A necessidade de implementação dos direitos humanos mediante a criação de um sistema internacional de monitoramento e controle não substitui os tribunais internos e não são tribunais de recurso ou cassação, mas os atos internos dos Estados podem vir a ser sim, objeto de exame dos tribunais internacionais, dessa forma a relação do Estado com os seus nacionais passa a ser uma problemática internacional.

Neste sentido, a Corte entendeu que o exame da Lei de Anistia para saber se está de acordo com a Constituição Nacional do Estado é questão de direito interno que não lhe compete, porém é sua competência e dever realizar um controle de convencionalidade, ou seja, analisar a compatibilidade, ou não, daquela lei com as obrigações internacionais do Brasil contidas na Convenção Americana.

Assim, a Corte entendeu que as disposições da Lei de Anistia brasileira que impedem a investigação e sanção de graves violações de direitos humanos são incompatíveis com a Convenção Americana e não podem ser obstáculo para a investigação dos fatos nem para a identificação e punição dos responsáveis. Portanto o Brasil deve realizar a investigação penal dos fatos ocorridos durante a ditadura militar, com o objetivo de esclarecê-los, determinar as responsabilidades penais e aplicar as devidas sanções.

Interessante observar que além das condenações acima descritas, a Corte, ao final da sentença, faz algumas importantes recomendações ao Brasil no sen- 
tido de esclarecer as violações aos direitos humanos ocorridos não só no Caso Araguaia, mas durante o período da ditadura militar, punir os responsáveis e com um intuito pedagógico, atuar preventivamente para que novas violações não aconteçam.

Neste sentido decidiu que o Brasil deve realizar todos os esforços para determinar o paradeiro das vítimas desaparecidas e, se for o caso, identificar e entregar os restos mortais a seus familiares e realizar um ato público de reconhecimento de responsabilidade internacional a respeito dos fatos do Caso Araguaia.

Condenou, também, o Estado a tipificar o delito de desaparecimento forçado de pessoas em conformidade com os parâmetros internacionais e interamericanos.

Afirmou que o Brasil deve desenvolver as iniciativas de busca, sistematização e publicação de toda a informação sobre a Guerrilha do Araguaia, assim como da informação relativa a violações de direitos humanos ocorridas durante o regime militar, o que serviu de base para a criação da Comissão de Verdade.

Enfim, cumpriu, a Corte, neste caso, o seu papel de órgão de proteção dos direitos humanos. Sua decisão tem força jurídica vinculante e obrigatória, cabendo ao Estado seu imediato cumprimento.

A efetividade da proteção dos direitos humanos no Brasil está absolutamente condicionada ao aperfeiçoamento das medidas nacionais de implementação e ao resgate do compromisso do Estado com as vítimas das violações aos direitos humanos ocorridas no período da ditadura militar. As reminiscências do regime autoritário, com uma cultura de violência e impunidade, ainda é muito presente no nosso país e precisa ser passada a limpo.

\section{Pesouisas do Editorial}

\section{Veja também Doutrina}

- A anistia e os crimes contra a humanidade, de Edson Luis de Almeida - RBCCrim 55/315;

- A declaração de inconvencionalidade da Lei de Anistia brasileira pela Corte Interamericana de Direitos Humanos no Caso Gomes Lund e outros vs. Brasil (Guerrilha do Araguaia), de Deo Campos Dutra - RT 920/183; e

- Lei de Anistia: um debate imprescindivel, de Pierpaolo Cruz Bottini e Igor Tamasauskas - RBCCrim 77/101. 